\title{
Quantity of reinforcement and fixed-interval performance
}

DONALD MELTZER and JAMES A. BRAHLEK, Department of Psychology, Southern Illinois University, Carbondale, Illinois 62901

Two groups $(N=5)$ of hybrid-strain rats were conditioned to press a lever on a fixed-interval $3 \mathrm{~min}$ schedule of food reinforcement. For the Ss in one group, reinforcement was three $45 \mathrm{mg}$ food pellets, and for Ss in the other group, reinforcement was one $45 \mathrm{mg}$ food pellet. Both groups showed an accelerated response rate during successive quarters of the interreinforcement interval, but the rate of acceleration was greater for the 3-pellet group. The mean percentage of total responses in an interval quarter was, however, the same for both groups, indicating that an increase in reinforcement quantity multiplies response rate during the interreinforcement interval by a constant factor.

Although quantity or quality of reinforcement has often been varied in studies of free operant behavior (e.g., Collier \& Meyers, 1961; Guttman, 1954), relatively few experimenters have studied the effects of these variables on responding maintained by a fixed-interval reinforcement schedule.

Hutt (1954), in a study of fixed-interval responding, showed that mean response rate increased with increases in both the quality and the quantity of a liquid reinforcer. Similarly, Stebbins, Mead, \& Martin (1959), using a within-S procedure, reported that the mean response rate on a fixed-interval reinforcement schedule increased as the concentration of the sucrose reinforcer increased.

Stebbins et al also reported that the distribution of responses within an interreinforcement interval depended on the sucrose concentration of the reinforcer. As sucrose concentration increased from $5 \%$ to $32 \%$, the percentage of responses made early in the interreinforcement interval increased, and the percentage made late in the interval decreased. Since the mean response rate increased as well with greater sucrose concentration, the implication is that the increase in response rate occurred at least partly because the Ss made more responses early in the interreinforcement interval at the higher sucrose concentration.

In the present experiment, a between-S procedure was used to study the effects of two quantities of reinforcement on fixedinterval responding. We were specifically interested in examining differences in the interreinforcement response distributions associated with the two reinforcement quantities.

\section{METHOD}

\section{Subjects}

Ten male, hooded rats of a hybrid strain bred in our laboratory were the Ss. Each S was 90-100 days old at the beginning of the experiment and was placed on a 22 -h food deprivation schedule one week before the first experimental session. Water was always available to an $S$ except for the time it was in the experimental chamber.

Apparatus

The experiment was run in a Skinner box (Lehigh Valley No. 1316) with interior dimensions of $7-1 / 2$ in. $x 12$ in. $x 8$ in. $A$ single response lever was located $1-3 / 16$ in. above the grid floor and $1-1 / 2$ in. from the right side of the box. The food hopper was located midway along the base of the front wall, and $45 \mathrm{mg}$ Noyes pellets were used as reinforcement.

Masking white noise was always present in the room in which the experimental chamber was located. All the programming and recording equipment was in an adjacent room.

Procedure

Each $S$ was given one to three 1-h sessions of continuous reinforcement in which each lever press produced one food pellet. The reinforcement schedule was then changed to fixed-interval 3 min. Two groups were randomly formed with five Ss in each. For the 1-pellet group the reinforcement was one $45 \mathrm{mg}$ pellet delivered immediately after the lever press. For the 3-pellet group the reinforcement consisted of three $45 \mathrm{mg}$ pellets. One pellet was delivered immediately after the lever press. A second pellet was Psychon. Sci., 1968, Vol. 12 (5) delivered $0.2 \mathrm{sec}$ after the first and a third pellet was delivered 0.2 sec after the second. Sessions lasted until the $S$ had received a total of 15 reinforcements which amounted to 15 pellets per session for the 1-pellet group and 45 pellets per session for the 3-pellet group. All Ss were run daily for 23 days.

\section{RESULTS}

The first column in Table 1 shows the mean rate of lever pressing during consecutive quarters of the last 70 interreinforcement intervals (last five days) of the experiment. The rate data were submitted to a two-factor (reinforcement quantity and quarter of interreinforcement interval) analysis of variance (Winer, 1962, p. 302). The analysis revealed that both reinforcement groups pressed more frequently as the interreinforcement interval progressed $(F=44.9$, $\mathrm{df}=3 / 24, \mathrm{p}<.001)$, which is typical of behavior that is reinforced on a fixed-interval schedule. There was no reliable difference in the mean response rates during an interreinforcement interval for the two reinforcement groups. However, the interaction between reinforcement quantity and quarter of the interreinforcement interval was significant $(\mathrm{F}=3.23$, df $=3 / 24, \mathrm{p}<.05)$.

This interaction was further analyzed using the $t$ statistic to test the difference in the mean response rates of the two reinforcement groups in each quarter of the interreinforcement interval. The $t$ tests showed that the mean response rates were not reliably different for the two reinforcement groups during Quarters 1, 2, and 3 of the interreinforcement interval. During Quarter 4 , however, Ss in the 3-pellet group responded at a higher mean rate $(t=2.01, \mathrm{df}=8, \mathrm{p}<.05)$ than $\mathrm{Ss}$ in the 1-pellet group.

The second column of Table 1 shows the data calculated as the percentage of total responses in each quarter of the interreinforcement interval. Although the difference in absolute response rate between the two groups increased as the interval progressed, there was no comparable difference in the percentage distribution of each group's responses within the interval.

The last column of Table 1 was obtained by dividing the 3-pellet response rate by the 1-pellet response rate at each interval quarter. These ratios show that, with the exception of Quarter 1, the effect of three pellets as opposed to one pellet was to increase response rate by a factor of approximately 1.6. The ratio of .7 obtained for Quarter 1 is probably not as reliable as the other ratios because of the small numbers of responses involved in its computation.

\section{DISCUSSION}

These data show that a larger reinforcement quantity increased the response rate in the last quarter of the interval but did not alter the percentage of total responses made in successive quarters of the interreinforcement interval. One of the frequently cited explanations of fixed-interval behavior (Dews, 1962) asserts that the rate increase during the ininterreinforcement interval is based on a delay of reinforcement gradient. There is a long delay early in the interval which causes a low probability of response, but as the interval progresses there is a steady decrease in delay which produces a steady increase in response probability. If it is assumed that the percentage distribution of responses accurately reflects the shape of the delay of reinforcement gradient, it is apparent that different reinforcement quantities did not affect the shape of the gradient in this experiment. However, the different reinforcement quantities did affect the probability of response.

Table 1

Response Rate, Per Cent Response, and Ratio of 3-Pellet to 1-Pellet Response Rate in Quarters of the Interreinforcement Interval

\begin{tabular}{|c|c|c|c|c|c|}
\hline \multirow{2}{*}{$\begin{array}{l}\text { Interval } \\
\text { Quarter }\end{array}$} & \multicolumn{2}{|c|}{ Rate (Rs/45 sec) } & \multicolumn{2}{|c|}{$\%$ Total Responses } & \multirow{2}{*}{$\begin{array}{l}\text { Ratio of 3- to } \\
\text { 1-Pellet Rate }\end{array}$} \\
\hline & 3-Pellets & 1-Pellet & 3-Pellets & 1-Pellet & \\
\hline 1 & 3.0 & 4.1 & 2.3 & 5.0 & .7 \\
\hline 2 & 9.1 & 6.7 & 6.9 & 8.2 & 1.4 \\
\hline 3 & 42.6 & 25.0 & 32.9 & 30.7 & 1.7 \\
\hline 4 & 75.0 & 45.7 & 57.9 & 56.1 & 1.6 \\
\hline
\end{tabular}


For example, the 1-pellet group's low rate in the second quarter of the interreinforcement interval was multiplied by 1.4 to match the rate in the 3-pellet group, but the absolute differences in response rate were quite small. During the final quarter of the interval, the response rate of the 1-pellet group was multiplied by 1.7 to match the response rate of the 3-pellet group, but the absolute differences in rate were large. Since the multiplier was nearly constant, the percentage distribution of both groups remained the same while differences in response rate increased as the interval progressed.

The results of the present experiment and the Stebbins et al (1959) experiment agree that the distribution of responses on a fixed-interval reinforcement schedule varies with quantity of reinforcement. However, the two experiments disagree on how the percentage of response distribution changes as a function of reinforcement quantity. There are several possible explanations for these different results, two of which are of particular importance. In the present experiment, the effect of different numbers of food pellets was observed using a between-S procedure. In the Stebbins et al experiment, the effect of different sucrose concentrations was observed using a within-S procedure. Either variable, number of food pellets vs sucrose concentration or between-S vs within-S procedure, might account for the difference in results between the two experiments.

\section{REFERENCES}

COLLIER, G., \& MEYERS, L. The loci of reinforcement. Journal of Experimental Psychology, 1961, 61, 57-66.

DEWS, P. B. The effect of multiple $S \triangle$ periods on responding on a fixed-interval schedule. Journal of the Experimental Analysis of Behavior. 1962, 5, 369-374.

GUTTMAN, N. Equal-reinforcement values for sucrose and glucose solutions compared with equal-sweetness values. Journal of Comparative \& Physiological Psychology. 1954, 47, 358-361.

HUTT, P. J. Rate of bar pressing as a function of quality and quantity of food reward. Journal of Comparative \& Physiological Psychology. 1954, 47, 235-239.

STEBBENS, W. C., MEAD, P. B., \& MARTIN, J. M. The relation of amount of reinforcement to performance under a fixed-interval schedule. Journal of the Experimental Analysis of Behavior. 1959, 2, 351-355. 